\title{
LA TEORÍA GENERAL DEL DERECHO FRENTE A LA ANTROPOLOGÍA POLÍTICA ${ }^{1}$
}

\author{
Óscar Correas \\ correas@servidor.unam.mx \\ $\mathrm{CEIICH}$ \\ Universidad Nacional Autónoma de México
}

\section{RESUMEN}

Este artículo tiende a mostrar que no es la Teoría General del Derecho, TGD, el obstáculo para el reconocimiento del pluralismo jurídico, sino más bien las necesidades de hegemonía del propio Estado moderno. La TGD contemporánea ofrece conceptos teóricos que permiten pensar el pluralismo jurídico, entendido aquí como el fenómeno de coexistencia de dos o más sistemas jurídicos que reclaman eficacia en un mismo territorio. También la dificultad para reconocer al sistema normativo indígena como «derecho» proviene de ideologías, como la de «soberanía», que no tienen plausibilidad teórica y que deben ser dejadas de lado por la ciencia social contemporánea. La eficacia del sistema jurídico dominante proviene, entre otras cosas, precisamente de la ideología en que son educados los juristas. Si las normas válidas son las que tienen efectividad y pertenecen a un sistema eficaz, como quiere TGD, entonces como las normas del derecho indígena son las eficaces, son también las válidas. Sin embargo esta validez es desconocida por los funcionarios del sistema hegemónico, que no han sido educados para pensar en la posibilidad del pluralismo jurídico.

Palabras clave: derecho indígena, Teoría General del Derecho, pluralismo jurídico, Antropología política, Estado moderno. 


\section{SUMMARY}

The article tends to demonstrate that GTL is not the obstacle for recognition of juridical pluralism, but rather the hegemonic needs of the modern State itself. Contemporary General Theory of Law (GTL) offers theoretical concepts that may be used by coexistence of two or more juridical systems that demand efficacy in a same territory. Also the difficulty to recognize the indigenous normative system as law stems from ideologies, such as that of sovereignty, that have no theoretical plausibility and should be left aside by contemporary social science. The effectiveness of the dominant juridical system originates out of, among other things, precisely the ideology in which lawyers are educated. If the valid norms are those with effectiveness and that pertain to an effective system, as GTL poses, then, given that the indigenous law norms are those that are effective, they are also those that are valid. However, this validity is ignored by the functionaries of the hegemonic system, who have not been educated to ponder the possibility of juridical plurality.

Key words: indigenous law, General Theory of Law, juridical pluralism, Legal, Anthropology, Modern state. 


\section{INTRODUCCIÓN}

Desde hace algún tiempo algunos juristas de IIJ-UNAM hemos comenzado a tomar contacto con antropólogos, habiéndose revelado intereses científicos comunes, encarados, no obstante, desde disciplinas que, más temprano que tarde, deben encontrar vías de colaboración si es que han de progresar de manera significativa en la compresión de los fenómenos normativos. Este trabajo tiene la intención de mostrar a los colegas antropólogos algunos desarrollos contemporáneos de la Teoría General del Derecho, TGD, que, a mi juicio, mejorarían el aparato conceptual con que se acercan a esos fenómenos normativos. Pretendo aportar elementos, desde TGD, de utilidad para los antropólogos con los que definir los conceptos de Derecho, normas, sistema normativo, conductas, costumbre, pluralidad jurídica, y derecho alternativo, todo lo cual podría redundar en beneficio de esta esperada cuanto siempre postergada relación intelectual entre juristas, sociólogos y antropólogos. Se trata aquí de las respuestas que la Teoría General del Derecho puede aportar a esos colegas, en temas como el pluralismo normativo y el llamado Derecho indígena.

Buena parte de los antropólogos se dedica a lo que solemos denominar Derecho indígena, que es una expresión que puede entenderse en varios sentidos. Por lo que respecta a este trabajo, servirá para referir el conjunto de las normas efectivas y eficaces ${ }^{2}$ en comunidades que contienen, en grado variable, elementos culturales indígenas, dejando para los colegas antropólogos la definición de este último concepto. Para el razonamiento que se intenta aquí esta idea es suficiente.

Lo primero que es necesario decir es que los científicos sociales deben comprender que el desprecio que sienten hacia el saber de ciertos juristas que no consigue ver el Derecho más que como un conjunto de leyes, si bien puede ser justificado, de todos modos no debe alcanzar a la teoría contemporánea del Derecho, la cual, por otra parte, ni ha sido creada por esos juristas ni es utilizada por ellos. El diálogo, por tanto, no será con esos abogados, sino con juristas que, además, están interesados en la Filosofía y las ciencias sociales. 
Convendrá primero poner a punto una concepción del Derecho que, partiendo de las adquisiciones de la TGD contemporánea, pueda sentar las bases de ese diálogo. Parte de los malos entendidos se asientan en que los científicos sociales toman como interlocutores a los juristas que actúan, más que como científicos del Derecho, como «objeto» de la ciencia jurídica. En efecto, toman por ciencia jurídica lo que escriben los juristas dogmáticos, sin saber que la TGD, actualmente, es más una «crítica» de lo que los juristas hacen que un cuerpo teórico que orienta su trabajo. La razón de esto, que debe parecerles un desatino, es que en la facultad de Derecho no se hace ni enseña ninguna ciencia, sino una técnica al servicio del poder. Seguramente se sentirían extrañados al saber que, con contadas excepciones, quienes se dedican a la Teoría del Derecho, la Sociología Jurídica, la Filosofía del Derecho, a veces incluso la Historia del Derecho, son acreedores de una enorme cuanto explicable antipatía por parte de las autoridades y el grueso de los profesores de las facultades de Derecho. Este es un fenómeno universal. No es patrimonio de ningún «ser nacional». Esta antipatía radica precisamente en uno de los hechos de que pretende dar cuenta este trabajo: la mal llamada ciencia jurídica «es parte constitutiva y sine qua non del ejercicio del poder».

\section{UN CONCEPTO SOCIOLÓGICO DEL DERECHO}

El Derecho es un fenómeno del lenguaje, tanto como «fenómeno» pueda ser el lenguaje. Conviene definirlo como «discurso prescriptivo autorizado, que organiza y por ello legitima la violencia, y que es reconocido como tal». ${ }^{3}$

\section{EL DERECHO ES DISCURSO PRESCRIPTIVO}

Por «discurso» debe entenderse «ideología formalizada en algún lenguaje», a sabiendas de que la Semiología puede profundizar más en esta cuestión. Este discurso es producto de un «uso prescriptivo del lenguaje», es decir, del que se realiza con la expresa intención de dirigirse a la conducta de otros para determinarla. Pero se diferencia de otros, como la moral, en que el Derecho amenaza con la violencia que desencadenará contra el desobediente, alguien a quien, precisamente por ser señalado por este discurso, se convierte en «funcionario público». 


\section{LA AMENAZA DE LA VIOLENCIA}

Por «violencia» debe entenderse no solo el ejercicio de la fuerza sobre el cuerpo de alguien, sino todas las formas de compulsión que son socialmente temidas. «Socialmente temidas» porque la compulsión se remite a mecanismos sicológicos construidos socialmente. En distintas sociedades la violencia tiene distintas apariencias. Antropólogos han hecho notar que en el Derecho indígena la violencia no siempre está presente. Lo que sucede es que esas normas no amenazan con los mismos males con que lo hacen nuestras normas. No es que no haya violencia, sino que tiene distinta apariencia. Precisamente que el Derecho indígena tenga más efectividad que el nuestro se explica porque la compulsión, no siendo la misma violencia física, es aún más poderosa que ésta.

\section{LA AUTORIZACIÓN DEL DISCURSO. LOS FUNCIONARIOS}

Todo derecho establece sus funcionarios. Son tales esos actores sociales que, siendo al mismo tiempo individuos como los demás, son señalados por el discurso del Derecho como aquéllos cuyas acciones no serán reputadas como propias, individuales, sino como siendo «de la comunidad». Lo único que diferencia la acción de verdugo de la del criminal es que una norma dice que la del primero es un acto del Estado y la otra un delito. La actuación del funcionario indígena que, en obediencia de órdenes de sus superiores, aplica una sanción corporal a un individuo de su comunidad, es vista como delito por parte del Derecho dominante. Pero la acción, en sí misma, no tiene ninguna diferencia con la que produce el carcelero del sistema jurídico hegemónico. Para éste, aquel funcionario es un delincuente. Pero para el sistema indígena es una autoridad.

En el mundo comunitario, en el que describen los antropólogos como «indígena», se encuentran claramente delimitadas las conductas que son vistas como pertenecientes a la comunidad. Sin embargo los individuos que cumplen conductas de funcionarios indígenas no siempre, más bien casi nunca, están separados del resto de la comunidad. Frecuentemente trabajan como cualquier otro, y casi nunca perciben alguna retribución. ${ }^{4}$ 
Vale una digresión. Los antropólogos están muy impresionados por lo que llaman «sistema de cargos». La expresión debe parecerles una que constata alguna diferencia con el Derecho hegemónico, esto es, el nuestro. Y cuando se les pregunta cuál es la diferencia con este último contestan que en las comunidades quienes desempeñan los cargos no cobran ningún estipendio. Y, claro, ven que entre nosotros los cargos son remunerados. Y eso les parece constituir la diferencia específica entre una y otra forma de organización.

La verdad es que la gratuidad es solamente la apariencia de otra cosa mucho más profunda, y que ha sido destacada por TGD. Lo que en verdad sucede es que pueden detectarse dos formas de organización jurídica. La primera, llamada «sistema descentralizado», consiste en que la sanción está encargada a individuos que no están especializados en ello; es decir, que no forman un grupo específicamente separado del resto de la población. La segunda, llamada «sistema centralizado», se caracteriza por la separación y especialización de una parte de la población, que tiene como encargo, como «tarea» específica, la aplicación de las leyes. Esto es, la sanción que siempre promete todo derecho. La onerosidad o gratuidad, de los cargos, es, por tanto, una consecuencia del carácter centralizado o descentralizado de la organización normativa —en verdad, «organización»y «normativa» son sinónimos—. ${ }^{5}$ No es «lo característico» de los cargos en las comunidades, sino un efecto de lo característico. Es decir: es cierto que en las comunidades los cargos se desempeñan gratuitamente, y entre nosotros de manera onerosa. Pero es la «apariencia» del fenómeno social que corre por debajo de lo aparente.

En las comunidades no existen individuos, ocultos tras las máscaras jurídicas, ${ }^{6}$ que tengan como función social, como tarea, la de aplicar el Derecho a los demás integrantes del grupo. Entre nosotros, en cambio, sí existen individuos que, desempeñando la tarea detrás de las máscaras, tienen la especial tarea de aplicar el Derecho, sus sanciones, a los demás miembro de la sociedad.

En las comunidades, con sistemas jurídicos descentralizados, no existen individuos «separados de la producción» que se ocupen específicamente de ciertas tareas «comunes». 
Entre nosotros, habitantes de un sistema jurídico centralizado, existen individuos «separados de la producción» que tienen a su «cargo» — y solo ellos pueden hacerlociertas tareas que llamamos «públicas». Estas tareas son diversas, y su mayor diversidad depende de la mayor complejidad de las sociedades organizadas en sistemas centralizados. Y la principal tarea es la represión: los «guardias» armados, que tienen el monopolio del uso de la fuerza, están netamente separados del resto del pueblo. ${ }^{7}$

Las bases sobre las cuales se levantan estas formas, centralizadas o descentralizadas, de organización jurídica, son de origen económico. Las comunidades, que no están fracturadas por la lucha de clases, no requieren cuerpos especiales de represión; ni los «cargos» están relacionados con la producción o la apropiación del producto social. En cambio entre nosotros, habitantes de una sociedad dividida en clases sociales, es completamente necesario, para la pervivencia del orden explotador, que la violencia sea centralizada, monopolizada, por cuerpos de «guardias» del «orden» público — léase «el orden de la explotación de una mayoría por parte de una minoría»- Es claro que, siendo la nuestra una sociedad en la cual la ganancia y la explotación del trabajo ajeno son el único motor social, su resultado no es otro que la lucha de clases. Y es claro que la clase dominante ha organizado cuerpos represivos —ejércitos, policías, jueces, fiscales- cuya tarea es monopolizar el uso de la fuerza. Y es claro por qué tienen que estar separados del pueblo. Es claro por qué son mantenidos con parte del producto social, que es extraído a los dominados, por la elegante vía del «sistema impositivo» 8.

Las comunidades no capitalistas desconocen el flagelo de los sistemas normativos centralizados, pues se organizan sobre la base de la igualdad de sus miembros y de la no explotación de trabajo ajeno. Tal organización no requiere de cuerpos especializados de represión ni de funcionarios especializados en la dificultosa y complicada administración de personas y cosas, propias de las sociedades capitalistas, mercantiles e industriales, cada vez más complejas, y cada vez más necesitadas del recurso de la represión. 
Las comunidades, no requiriendo de cuerpos especiales de represión —porque no hay explotación del trabajo ajeno- y administración —porque la producción es simple, «natural» «impuestos». La tarea de aplicar la ley y administrar las cosas de la comunidad es gratuita, porque no hay «finanzas públicas»; no se requiere retirar a nadie de la producción, ni exaccionar a nadie en nombre de la comunidad para pagar con ello cuerpos especiales de represión o administración. Los cargos comunitarios son gratuitos, por tanto, debido a las condiciones de producción y reproducción de la vida comunitaria. Mirar los cargos, sin mirar la vida productiva, conduce a la no comprensión del fenómeno social subyacente. Parece que las comunidades lo son por virtud de algún milagro ideológico. Pero lo son porque se reproducen de una cierta manera especial.

La gratuidad de los cargos en las comunidades indígenas, por tanto, es solamente lo aparente de lo que corre por debajo, que es la condición no explotadora de la producción. Los «cargos» en la comunidad son, por una parte, iguales a los nuestros: en ambos casos, los funcionarios deben cumplir ciertas conductas. Pero unos cargos se sirven en forma gratuita, y otros en forma onerosa. ¿Por qué? Si se mira solamente la gratuidad o la remuneración, el estudio quedará sin explicaciones plausibles.

El discurso del Derecho, al «crear» a los funcionarios, «autoriza» su discurso «como» jurídico. Es decir, lo que el Derecho cumple es la tarea de hacer que el discurso del funcionario sea legitimado como «debido», legitimando la sanción que corresponderá al desobediente. De allí que los juristas manifiesten la tendencia a sostener que es Derecho, y que por tanto debe cumplirse, todo discurso prescriptivo producido por funcionarios autorizados debidamente por una norma anterior. Veremos que en esto último hay una trampa.

Se comprende mejor ahora por qué el principal teórico de este siglo, Hans Kelsen, ha sostenido que Derecho y Estado son la misma cosa. En efecto, el Estado no es alguna cosa 
mágica, existente por encima y más allá de los seres de carne y hueso. Eso es, ni más ni menos, una hipostatización. El Estado no es otra cosa que el conjunto de las acciones de ciertos individuos, que el discurso dice que no son acciones de ellos sino de la comunidad o «Estado». Puede decirse, en el mismo venero, que el Estado es un efecto del uso del lenguaje. Esto abre el camino para entender la posibilidad del pluralismo jurídico o multiplicidad de Estados, algunos de los cuales hegemonizan a otros. Volveremos sobre esto.

Tenemos entonces un discurso prescriptivo, autorizado, que amenaza con la violencia, que establece sus propios funcionarios. Ciertamente que así dicho pareciera que se sostiene que el Derecho es un discurso sin productor. Aunque en cierto sentido así es, de todos modos no deja de ser claro que hay «alguien» que lo produce y que pretende ser obedecido, que pretende la «hegemonía» en la sociedad de que se trate. Ese «alguien», su rostro, tiene que ser descubierto por las ciencias sociales. La TGD no puede ir más allá. Sólo en concreto, la Sociología, la Antropología, la Sociología jurídica, pueden aportar novedades. La TGD, para ser tal «teoría», no puede ir más allá de señalar, claramente desde luego, cosa que algunos teóricos «olvidan» decir y sobre todo enseñar, la presencia de un productor del discurso.

Es tarea de las otras ciencias sociales establecer el peso específico de los distintos grupos y clases sociales en la determinación del «contenido» de las normas. Cuando TGD dice que existe un productor del discurso, de ninguna manera quiere decir que ese «productor» sea una persona, un solo grupo social, o que los dominados no tengan participación en la creación del Derecho. 


\section{EL RECONOCIMIENTO DEL DISCURSO DEL DERECHO}

Finalmente, este discurso prescriptivo especial, para ser Derecho, debe ser reconocido como tal. No tendría ningún interés científico estudiar discursos prescriptivos que no cumplen el cometido de hacer que alguien haga algo. Es decir, el discurso de que hablamos tiene una efectividad y una eficacia propias. Como veremos enseguida, las normas lo son siempre que tengan un grado importante de efectividad y pertenezcan a un sistema eficaz.

La TGD contemporánea ha destacado suficientemente que no es Derecho el discurso de alguien que se pretende funcionario, sino solamente si ese discurso tiene alguna efectividad. Así, algunos teóricos han sostenido que Derecho es lo que dicen los jueces y no el legislador. Otros han sostenido que Derecho es el conjunto de normas que son vividas, sicológicamente vividas, como obligatorias por la población y, desde luego, también por los jueces y demás funcionarios públicos. Como se ve, a diferencia de lo que se enseña en las facultades de Derecho, la teoría no considera interesante definir este concepto sobre la base de lo producido por el poder, sino más bien sobre la base de lo que realmente, «sociológicamente» digamos, sucede.

\section{LAS NORMAS JURÍDICAS Y EL DISCURSO DEL DERECHO}

\section{LAS NORMAS}

Para TGD, las normas son construcciones lingüísticas que consisten en la modalización deóntica de — la descripción de — una conducta. Por ejemplo, «obligatorio prestar trabajo comunitario» es una norma en la que se distingue el modalizador deóntico «obligatorio» y la descripción de una conducta: «prestar trabajo». Una norma, entonces, se simboliza como Op, Pp, Ap o Vp —Obligatorio, Permitido, Autorizado, o Prohibido «p», que es la descripción de la conducta. 


\section{SENTIDO DEÓNTICO Y SENTIDO IDEOLÓGICO}

Es interesante notar que el Derecho existe en textos, escritos u orales, en el interior de los cuales deben ubicarse, encontrarse, las normas. Casi nunca se encuentra un texto en el que la normas aparece en la forma canónica de Op o «si sucede A, entonces un funcionario de la comunidad debe aplicar cierta sanción $\mathrm{B} »$. Por el contrario, y mucho más cuando se trata del tipo de textos que estudian los antropólogos, las normas están como escondidas en discursos que contienen otras ideologías, a veces sumamente complejas y difíciles de analizar. El antropólogo puede ser el mejor testigo de que, para saber cuáles son las normas de una comunidad, es necesario hacer complicados análisis para desentrañarlas del abigarrado texto lleno de símbolos y mitos. En realidad, el abogado moderno también procede así: se enfrenta a complicados textos que dicen tener cierta intención pero luego la desmienten en las normas que crean. Y en ese mare magnum de palabras, aquí sí, escritas, debe navegar hasta encontrar las normas que le permiten solucionar un caso. No es cierto que las normas estén claramente establecidas en la legislación escrita. Si eso fuese verdad, entonces nunca se daría el conflicto por interpretaciones distintas de los textos. Y si algo prueba la experiencia jurídica es que todos los días hay esas múltiples interpretaciones de los textos.

Llamaremos sentido deóntico del discurso del Derecho a esas normas que, luego de un trabajo intelectual a veces importante, pueden encontrarse en los textos que se presentan, a primera vista, como «del Derecho». Y llamaremos sentido ideológico del discurso del Derecho a cualquier otro mensaje que pueda leerse en tales textos. Los antropólogos saben mucho de esto: es su oficio estudiar la ideología en que vienen envueltas, las que llama «costumbres».

\section{NORMAS ESCRITAS Y NO ESCRITAS. LA COSTUMBRE}

Lamentablemente los antropólogos, siguiendo a los juristas precisamente en lo que no debieran seguirlos, usan la palabra «costumbre» para referirse a las normas no escritas. Lo primero que habría que hacer es dejar de lado ese término confuso y hablar, simplemente, 
de derecho escrito y no escrito. Con ello se terminaría la lamentable cuanto inútil discusión acerca de si las normas de las comunidades son o no Derecho, y acerca de la diferencia entre Derecho y costumbre. Lo único que habría que hacer es preguntarse, frente a los textos normativos, escritos o no escritos, es si responden o no a las características de la definición de Derecho. Y conforme con nuestra definición, lo que los antropólogos observan en las comunidades $i$ son discursos prescriptivos, que amenazan con la violencia, que crean funcionarios, y que son reconocidos como obligatorios por la comunidad? Si lo observado responde con el concepto, entonces es Derecho, esté o no escrito, digan lo que digan los funcionarios del Estado dominante, digan lo que digan los textos de los juristas.

\section{NORMAS Y CONDUCTAS}

Los antropólogos, pero también otros cientistas sociales $-\mathrm{y}$ algunos juristas también-, cometen el lamentable error de confundir las normas con las conductas. Sobre todo cuando las normas son no escritas. Cuando se ensaya preguntarles a qué se refieren con la palabra «costumbre», dicen, invariablemente, que se refieren a lo que la gente hace. Si ven que los miembros de la comunidad proporcionan trabajo gratuito, entonces dicen que existe la costumbre de dar el tequio o servicio. Pero hay aquí un error grave: las normas no pueden observarse. Lo que puede observarse es la conducta de la gente, no las ideas que tienen sobre estas conductas. Y las normas, no escritas, consisten en las ideas deónticas acerca de éstas.

No debiera haber problemas para comprender, para estudiosos tan próximos a la lingüística, la diferencia entre hechos y sentido. Pero, sobre todo, debería ser claro que, si no se hace esa diferencia, entonces se pierde la oportunidad de observar, ahora sí, observar, la inefectividad de las normas y comprender su significado social. Si llamamos costumbre a la acción de prestar servicio gratuito, ¿cómo llamaremos a la acción que consiste en negarse a prestar tal servicio? ¿Acaso los antropólogos observan siempre que la gente siempre hace lo mismo? ¿No hay acaso procesos judiciales precisamente por incumplimiento de la «costumbre»? ¿Y cómo llaman a esa violación a la costumbre? ¿La descostumbre? Obsérvese que cuando el antropólogo decide ver una conducta como debida le llama 
costumbre a esa conducta; y cuando decide ver una conducta como violatoria de la costumbre, entonces «costumbre» readquiere el significado de norma. Es decir, en un caso usa la palabra para referir hechos, y en el otro para referir una norma o sentido. ${ }^{9}$

La diferencia entre normas y conducta, para la Antropología, pero también para la ciencia Política y la Sociología, es de la mayor importancia si queremos averiguar el grado en que el sistema normativo es eficaz, el grado en que un grupo mantiene hegemonía sobre otro.

Todo queda más claro si suprimimos el uso de «costumbre» reemplazándolo por Derecho no escrito, y si no perdemos de vista jamás la diferencia entre normas - escritas o no escritas - y conducta.

Finalmente cabe decir que, conforme con observaciones de la Sociología jurídica mexicana, resulta que no siempre las comunidades estudiadas desconocen totalmente la escritura. En muchos casos se toman resoluciones que son asentadas en actas, así como se asientan por escrito resoluciones y convenios producidos con motivo de procesos judiciales. Posiblemente la influencia del Derecho escrito sea hoy mucho mayor, en esas comunidades, que lo que nos dicen las informaciones antropológicas. Y eso provendría, creo, del no uso de categorías jurídicas más elaboradas.

\section{VALIDEZ, EFECTIVIDAD Y EFICACIA DEL DERECHO}

Los juristas teóricos discuten acaloradamente acerca de la validez de las normas. Lo que se preguntan es: ¿cuándo una norma es válida?, y al parecer están tratando de averiguar cuándo un enunciado que se presente como norma debe ser tomado por tal $\mathrm{y}$, en consecuencia, debe ser producida cierta conducta por parte de un funcionario. Como se comprende fácilmente, estamos ante el problema del reconocimiento del Derecho.

Según Kelsen, que una norma sea válida quiere decir que existe y que debe ser aplicada. Pero este «debe» no es moral. No es que el juez esté moralmente obligado a obedecer, podría ser que la norma le parezca injusta y, conforme con sus creencias morales, esté 
obligado a desobedecer. Este «debe» de Kelsen, en este caso, no tiene un significado claro. Nosotros podríamos decir que el debe es simplemente la amenaza de la violencia que se cierne sobre el juez si no aplica la norma. Lo cierto es que los juristas discuten sobre este concepto.

Pero también es cierto que algunos teóricos han sostenido que el concepto de validez es inocuo, que la ciencia no requiere tal categoría. Esto es porque consideran que el Derecho no debe ser buscado en lo que dice la autoridad, sino en lo que dicen o hacen quienes receptan ese mensaje y obran, o no, en consecuencia.

A mi juicio la mejor respuesta sigue siendo la sugerida por Kelsen: para que una norma sea válida, esto es, para que pueda decirse que si no es cumplida el obligado corre el riesgo de ser sancionado, es necesario que:

a) El discurso en el que se encuentra la norma haya sido producido por un funcionario autorizado a producir ese discurso y no otro.

b) La norma tenga algún grado, importante, de efectividad. Es decir, que los interpelados por ella produzcan la conducta obligatoria o se abstengan de la prohibida. Es claro que este criterio tiene dificultades respecto de las normas recientes; no se puede exigir efectividad a normas que no han tenido tiempo de ser aplicadas. En tal caso habría que hablar de Derecho «vigente», en el sentido de que existe la posibilidad de que algún funcionario lo cumpla o haga cumplir.

c) La norma forme parte de un sistema normativo eficaz. Y un sistema es tal cuando cumple la función de todo sistema normativo: reproducir el poder de quien produce el derecho. Y ¿cómo sabremos que el sistema cumple esa función? Debemos contestar: porque «observamos» que son efectivas la mayor parte de las normas de ese sistema.

Para algunos muy interesantes teóricos el primer requisito sobra. Sin embargo, para una TGD que entienda a su objeto como parte principal del fenómeno del poder, resulta ineludible considerar el momento de la producción del discurso, precisamente para poder medir luego la hegemonía del grupo que en el poder produce el Derecho. Si sólo nos 
quedamos con el cumplimiento de las normas, tendremos una teoría plausible, pero perderemos de vista la comparación entre lo que el poder quiere y lo que consigue.

\section{LA NORMA FUNDANTE}

Que un sistema normativo sea eficaz o no es una cuestión de hecho, de observación sociológica. Sin embargo esa simple observación no contesta a una pregunta que los juristas no pueden dejar de hacerse. Si una norma es válida cuando es, en primer lugar, producida conforme con otra anterior y superior, y si de esta puede decirse lo mismo, llegará un momento en que ya no pueda responderse con otra norma; por ejemplo cuando, subiendo, llegamos a la Constitución. Sabemos que las normas mexicanas son válidas porque, suponemos, han sido producidas conforme con la carta magna de 1917. Pero ¿por qué vale esa Constitución? ¿Quién dice, y con qué autoridad, que debemos ajustarnos a ella? Obsérvese que no es una pregunta sociológica, que no parece contestarse con los hechos que explican que Carranza y el ejército vencedor hayan conseguido imponer esa norma.

Esta pregunta puede ser formulada también así: ¿cómo sabemos cuáles son las normas que integran el sistema jurídico mexicano? O bien, ¿cómo saben los antropólogos cuáles son las normas que integran el sistema jurídico indígena? Claro, puede decirse, ellos preguntan a la gente. Pero ¿cómo lo sabe la gente? Los juristas han contestado diciendo que todo sistema contiene una norma - o tal vez varias-, que son usadas por la gente para reconocer las otras normas. Y llaman a esta norma «de reconocimiento». El planteo difiere algo del anterior, pero en el fondo pregunta por lo mismo: ¿cuál es el fundamento del sistema jurídico?

La respuesta sugerida por la teoría kelseniana me parece la mejor: en realidad no hay ningún fundamento. Lo que pasa es que, luego de producida la Constitución, las fuerzas sociales hegemónicas consiguen crear una conciencia generalizada de que esa norma debe ser obedecida, ya sea por temor, ya sea por convencimiento, pero principalmente por esto último. Kelsen dice que la norma fundante de un sistema jurídico, que no es la Constitución sino otra que la funda, es en realidad una ficción. Se trata de que actuamos como si la 
Constitución tuviera un fundamento. No podemos detenernos en esto, pero obsérvese que la pregunta sobre la validez del sistema en su conjunto, que no aparecía como sociológica, al final se convierte en tal. Un sistema normativo es válido cuando es eficaz. Y lo es cuando «la gente» actúa como si fuera válido. Es decir, la pregunta por la justificación de un sistema normativo no tiene respuesta externa al propio sistema. Pero puede observarse, desde el punto de vista externo, que el sistema es obedecido y que se ha desarrollado una ideología de aceptación del mismo.

\section{EL PLURALISMO JURÍDICO}

Tenemos ya, entonces, un conjunto de categorías brindadas por la TGD contemporánea. Con ellas podemos preguntarnos por el fenómeno que se ha denominado pluralismo jurídico. $^{10}$

El nombre sugiere ya la idea de que el sistema jurídico no es uno sino varios. ¿Es esto sostenible a la luz de la TGD? Sin duda que sí. Pero tropezamos aquí con una ideología fortísima que opaca la posibilidad de concebir la coexistencia de varios sistemas normativos en un mismo territorio. Esta ideología es la de soberanía. ${ }^{11}$

El concepto de «soberanía» tal vez se entiende mejor en francés. La souveranité aparece por oposición a la suzeranité. Esta última palabra, curiosamente, no tiene traducción al español, ni es utilizada con frecuencia en los textos de teoría política. Suzeranité designa, en el mundo feudal que habla francés, el estado de sujeción en que se encuentra un individuo respecto de otro; por ejemplo, la relación entre un señor y otro que, por ser suzerain, es «superior» al primero. También la relación entre señores y siervos. Y es posible que un señor sea souzerain respecto de algunos pero a la vez tenga un suzerain al que se encuentra sujeto. La red de «suzeranías» era todo lo complicada que es fácil de imaginar.

El concepto de «soberanía», en ese contexto, se utiliza para referir la pretensión de un señor de subsumir bajo su «suzeranía» a todas las demás. Frente a la soberanía del señor 
principal, el rey, debían caducar todas las otras. Es decir, el rey no reconoce otro poder por encima del suyo, y eso lo hace «soberano».

Pues bien; el Estado moderno es el heredero del rey y se ha constituido alrededor de la idea de soberanía: no hay ningún poder por encima de él. Poder ¿para qué? Para producir normas. «Soberanía» es un término eminentemente jurídico, quiere decir que las normas son producidas exclusivamente por el poder que, por eso, es «soberano». Esta ideología es tan fuerte que les impide a los juristas pensar en que, no al lado sino dentro mismo, haya otros sistemas jurídicos. Sólo consiguen concebirlos si el sistema estatal — para ellos hay un solo estado- los autoriza; aunque en tal caso ya no hay pluralismo de sistemas, sino uno solo.

Sin embargo un sistema normativo indígena cabe dentro de las definiciones que dan los propios juristas: conjunto de normas dotadas de poder coercitivo y producidas por funcionarios autorizados. ¿Cabe esto en los sistemas indígenas? Sin duda que sí. Esas comunidades usan un conjunto de normas que amenazan con la violencia, física o simbólica, y que son aplicadas por miembros perfectamente identificables como funcionarios ${ }^{12}$ de esos sistemas. Y si se trata de la pregunta acerca de si es Derecho el producido por el poder o el que se consigue hacer cumplir, también el Derecho indígena puede ser considerado de esa manera: podemos aceptar que las normas de la comunidad son las que dicen los ancianos o podemos aceptar que son las que efectivamente se cumplen. De cualquier manera un sistema normativo indígena cumple con los requisitos de la definición. ¿Por qué no aceptarlo entonces? Exclusivamente por razones políticas: no conviene aceptarlo; no puede aceptarse sin mengua del poder dominante. Pero no hay ninguna razón «científica», digamos.

Nosotros podemos aventurarnos a aplicar la definición a las comunidades indígenas. ¿Usan normas que amenazan con la violencia y que son cumplidas y hechas cumplir por funcionarios autorizados? ¿Sí? Entonces tienen un Derecho que, en su mayor parte, es no escrito, como en el caso de Estados Unidos y Gran Bretaña. 
Y ¿cómo debe verse el hecho de la coexistencia de dos poderes en el mismo territorio? Esta pregunta tiene dos clases de respuestas: las sociológicas y las jurídicas. Desde el primer punto de vista, no hay ningún inconveniente en aceptar que las comunidades indígenas son unas de las distintas fuerzas sociales que conviven en un territorio. Pero desde el otro punto de vista la pregunta es: las normas que crean ¿son «Derecho»? La pregunta, en realidad, esconde la ideología de la soberanía ¿Por qué no ha de ser Derecho?

La solución es más bien simple: se trata de sistemas jurídicos con distinto nivel de prestigio o, si se quiere, con distinto grado de hegemonía. La realidad muestra, a la luz de TGD, que hay pluralismo jurídico y que unos sistemas hegemonizan a otros, descollando uno en particular que, por eso, calificamos de dominante frente a los otros, que son subordinados. ¿Y el concepto de soberanía? En realidad es obsoleto para la ciencia social de finales del siglo $\mathrm{XX}$.

Definiremos el fenómeno del pluralismo jurídico como la coexistencia de dos o más sistemas normativos que pretenden validez en el mismo territorio. Que «pretenden», pues es una cuestión de hecho, que debe dejarse a la Sociología o la Antropología si consiguen o no eficacia.

Diremos que estamos frente a un Derecho alternativo respecto del dominante cuando pueda decirse que algunas normas de uno de los sistemas modalizan deónticamente de manera diferente las mismas conductas. Es decir, hay Derecho alternativo cuando las normas de un sistema declaran obligatorias conductas que el otro declara prohibidas o facultativas.

¿Es el Derecho indígena un Derecho alternativo? En la mayor parte de los casos sí. Sin embargo no suele ser un sistema subversivo en el sentido de que la plena eficacia del mismo no pone en peligro la eficacia general del sistema dominante. Si sucediera lo contrario, si la plena eficacia del sistema alternativo implicara la desaparición o ineficacia del sistema dominante, estaríamos en el caso de un sistema jurídico subversivo, como lo 
fueron los producidos por los insurgentes de la Independencia por los revolucionarios mexicanos de la segunda década de este siglo, o por el ejército rebelde comandado por Fidel Castro a finales de los cincuenta en Cuba.

\section{PLURALISMO JURÍDICO Y PLURALISMO ESTATAL}

El positivismo jurídico, cuando menos el encabezado por Kelsen, ha destacado desde sus primeras apariciones que el Estado no es otra cosa que el orden jurídico. El Estado no es ni el grupo de individuos que ocupan los cargos públicos, ni los cañones ni los edificios, sino las normas. Y entiéndase que para esta concepción las «instituciones» - a las que suelen referirse los sociólogos cuando eventualmente quieren definir el término «Estado»-, no son otra cosa que conjuntos de normas. Tampoco las instituciones son ni los funcionarios ni los edificios, sino las normas que regulan las actividades de esos sujetos y el uso que se hace de esos edificios.

Siendo así, que el estado es el derecho, bien puede decirse que donde hay dos sistemas jurídicos hay dos estados, sólo que uno es dominante respecto del otro. Para ser congruentes, los positivistas deberían acepar este terrible atentado contra la unidad y la soberanía del estado moderno. Dudo que lo hagan. Pero nosotros podemos avanzar en estas ideas y romper con el mito de la unidad del estado y con el obsoleto concepto de soberanía.

\section{EL SABER JURÍDICO Y EL DERECHO INDÍGENA}

Podemos hacer una diferencia útil entre lo que los juristas saben y hacen, y lo que sería una ciencia del Derecho si ésta se practicara conforme con los cánones normalmente aceptados por los científicos sociales, y con TGD. Puede ser sorprendente para los colegas de otras disciplinas esta diferencia que seguramente ellos no necesitan respecto de su práctica científica.

Conforme con TGD, como hemos visto, no hay inconvenientes para pensar el fenómeno del pluralismo jurídico y el Derecho alternativo. Sin embargo, hemos visto, los juristas no 
piensan lo mismo: para ellos sólo hay un Derecho y un Estado. Pero, con ser anticientífico su saber, no deja de tener enorme eficacia.

Este saber fluctúa como la teoría, y no hace sino intentar explicar al primero, entre considerar como Derecho lo establecido por el poder o lo cumplido por los obligados. Los abogados, en la universidad, aprenden lo primero, pero tan pronto salen a la calle comprenden que la verdad es que el Derecho es lo que dicen los funcionarios, principalmente los jueces. Ambas consideraciones conviven en el saber jurídico. Ahora bien, ¿qué tiene esto que ver con el pluralismo jurídico? Veamos.

¿Por qué pierden efectividad las normas del sistema indígena? ¿Por qué no son aplicadas las normas válidas de los sistemas indígenas por parte de los juristas, especialmente los jueces? ¿Acaso no saben los abogados que Derecho es, finalmente, lo que se consigue hacer cumplir? Si las efectivas son las normas del sistema indígena, ¿por qué no las aplican?

La respuesta está, claro, en su educación. Los abogados son la capa social especialmente entrenada para reconocer como Derecho lo que el poder quiere que sea reconocido como tal. Todas las sociedades tienen actores que cumplen esa función. También las comunidades indígenas los tienen. Una de las razones que explica la hegemonía de un sistema normativo sobre otro es el saber de quienes están encargados de constituir la eficacia del sistema. Por una parte, es necesario que los funcionarios del sistema que se quiere dominante tengan más fuerza, en el sentido de violencia, que los del sistema cuya eficacia se quiere destruir. Pero por otra parte, se requiere que, cuando el funcionario se encuentre frente a un conflicto que involucra a un ciudadano del otro sistema, esté dispuesto a «saber» que las normas aplicables son las de su sistema, aun cuando sepa que, conforme con su propio saber, las que deberían aplicarse son las efectivas, que son las del sistema indígena. Pero con ello ataca esa efectividad mientras que otorga efectividad a las del sistema que le paga. Es decir, se trata de un conflicto entre sistemas normativos, que pasa por la ideología de los funcionarios del hegemónico. 
Por eso es necesario combatir la idea de que el saber de los abogados es una ciencia «objetiva», como se exige a todas las demás. No es tal, porque ese saber es, en verdad, parte de la realidad que dice describir. En efecto, cuando se dice que esa «ciencia» describe normas válidas, resulta ser que, precisamente por considerarlas válidas, les otorga efectividad. Es decir, el resultado de ese saber constituye al objeto del saber.

\section{PLURALISMO JURÍDICO Y DOMINACIÓN}

Cabe la pregunta: ¿por qué unos sistemas hegemonizan a otros? Los antropólogos, en alguna de las contadas ocasiones en que hemos dialogado, dieron cuenta de casos en los que no resultaba del todo racional que el Estado mexicano hubiese gastado recursos en el castigo de actividades que no son delito conforme con el Derecho de la comunidad sobreviviente. Se trata de actos que, al parecer, no estorban el amplio dominio del Estado hegemónico. Todo podría seguir igual si no se reprimieran esas manifestaciones culturales que no producen daño «social», entendiendo por daño social uno que afecte a los ciudadanos del Estado hegemónico.

Por ejemplo, el caso del matrimonio, ¿qué le importa a nadie si en alguna comunidad existen formas de matrimonio por grupos, o de matriarcado, o de poligamia? ¿Qué le pone o qué le quita a los ciudadanos del Estado mexicano que en alguna comunidad un hombre tenga varias esposas, y que se reconozcan a todas ellas los derechos que les adjudica el sistema jurídico que obedecen? Incluso se trata de sitios apartados, sin ninguna publicidad, donde lo que sucede ni siquiera es conocido de manera que pueda producir daño «moral» por el «mal» ejemplo. Es comprensible el celo de los funcionarios del Estado hegemónico cuando se trata de violación de normas que tienen por objeto lograr la explotación de esas comunidades. Pero no parece serlo cuando la vida comunitaria no afecta el fondo del sistema capitalista. La respuesta es, parece, que la dominación tiende a ser completa, que no debe dejarse nada del patrimonio cultural del pueblo dominado, tampoco su Derecho. 


\section{TEORÍA, CIENCIA Y POLÍTICA}

Una pregunta distinta es ¿cómo deberían comportarse los funcionarios del sistema hegemónico? O, mejor, ¿es posible pensar que se comportarán de otro modo, es decir, permitiendo la pervivencia del sistema jurídico hegemonizado y, por tanto el pluralismo jurídico? Esto ya no es ciencia o filosofía, es política. La Sociología jurídica sólo puede aspirar a explicar el porqué se comportan así, y, sobre, todo, a constatar que la actuación del funcionario constituye la eficacia del sistema que lo inviste y al que obedece.

Pero, por su parte, TGD ¿tiene alguna responsabilidad en el comportamiento de esos funcionarios? ¿Puede decirse que actúan así, siguiendo alguna teoría jurídica? Pues el funcionario actúa así porque piensa que debe hacerlo de esa manera y no de otra. Es difícil decir que detrás de la acción de los funcionarios hay una «teoría» del Derecho. En todo caso no es la positivista y mucho menos la de Kelsen. Tampoco algunas de las diversas teorías que utilizan los sociólogos.

Más bien habría que decir que los funcionarios expresan, en su acción, una visión del mundo que excluye la posibilidad de la coexistencia de normas pertenecientes a distintos sistemas jurídicos en el mismo territorio. El Estado, heredero de la idea de soberanía, no puede resistir la competencia de otros sistemas normativos.

Sin embargo, puede observarse que esta concepción, si bien es muy conveniente para quienes detentan el poder, no responde a las evidencias empíricas de una sociedad moderna. Que esta última sea confundida con una que requiere ese Estado único es producto de una ideología cuidadosamente cultivada desde hace al menos dos siglos. En realidad, en toda sociedad moderna coexisten numerosos sistemas jurídicos, con diverso grado de hegemonía de cada uno sobre los otros. Lo que sí puede detectarse es la hegemonía de uno de ellos sobre todos los demás. Pero precisamente su hegemonía se basa, en parte, en la acción de sus funcionarios, cuidadosamente educados para reconocer como válido solamente ese sistema. Son esos funcionarios los que se erigen, a veces sin que nadie 
tenga verdadero interés en ello, en guardianes de la eficacia de las normas del sistema hegemónico.

Ahora bien, ¿podrían comportarse de otro modo, aceptando la posibilidad de que en el mismo territorio existan más de un sistema jurídico? En el caso del Derecho indígena, ¿podría el funcionario del sistema estatal hegemónico considerar que las normas del sistema indígena son válidas y por tanto aplicarlas o aceptar su aplicación?

Pareciera, a primera vista, que la respuesta pudiera ser positiva: el funcionario del sistema hegemónico podría considerar la validez de las normas del sistema jurídico indígena. Sin embargo, el funcionario destacado precisamente en ese territorio es uno de muy baja jerarquía y sabe perfectamente que pende sobre él la amenaza de destitución en caso de que un funcionario superior piense distinto. Pareciera que esto puede solucionarse con una reforma constitucional que obligue a los funcionarios del Estado hegemónico el considerar válidas las normas del Estado indígena. Sin embargo, a su vez, la eficacia de tal reforma requeriría del convencimiento de los miembros de la Suprema Corte de Justicia encargados de declarar la inconstitucionalidad de los actos de los funcionarios públicos.

Como se ve, la cuestión es que la existencia del sistema jurídico hegemónico incluye su propia eficacia. Esto es, no existe sistema jurídico si no es eficaz, y su eficacia consiste en que se cumplan las normas que lo componen. La eficacia del sistema jurídico que reconoce otros sistemas consistiría en que se reconozcan normas que no pertenecen al sistema de cuya eficacia hablamos. Esta aparente contradicción es la que está en el corazón del problema del pluralismo jurídico.

Sin embargo, desde el punto de vista de TGD no habría inconveniente en pensar en la coexistencia de varios sistemas jurídicos con la condición de que los funcionarios del sistema hegemónico cambien su visión del mundo jurídico, lo cual — pareciera- es una cuestión de educación. 
En cambio la Sociología jurídica muestra que el sistema jurídico hegemónico, el Estado moderno, que es soberano, resiste mal la competencia de otros sistemas aun cuando éstos sean mucho más débiles. Con mucha mayor razón, esto sucede cuando los sistemas alternativos son subversivos.

Lo comentado debería ser suficiente para mostrar que la moderna TGD no tiene dificultades para pensar y explicar la existencia de fenómenos de pluralismo jurídico, y que, al contrario, consigue explicar el porqué es el Estado moderno el que tiene dificultades para aceptar la competencia de otros sistemas. 


\section{BIBLIOGRAFÍA}

Correas, Óscar, 1993, Crítica de la ideología jurídica, UNAM, México.

1994, Introducción a la Sociología Jurídica, Fontamara, México.

2004, Pluralismo Jurídico, Alternatividad, y Derecho indígena, Ediciones Coyoacán, México.

2007, Derecho Indígena Mexicano I, Ediciones Coyoacán/UNAM-CeIICH, México.

Engels, Federico, 2000, El origen de la familia, la propiedad privada y el Estado, Editorial Progreso, s/f, Moscú, p. 173.

Kelsen, Hans, 2004, «Dios y Estado», en El otro Kelsen, de Óscar Correas, Ediciones Coyoacán/UNAM, México, pp. 243 y ss.

1988, Teoría General del Derecho y del Estado, capítulo primero, UNAM, México, p. 32.

Marx, Karl, 1978, El Capital, Siglo XXI, México.

Weber, Max, 1983, Economía y Sociedad, Fondo de Cultura Económica, México, p. 43. 
Notas

${ }^{1}$ Este artículo fue presentado en un coloquio organizado por el Instituto Nacional de Antropología e Historia, en 1994, no obstante una redacción anterior fue usada en un coloquio en Ajijic, en 1992, y antes en las Jornadas Lascasianas de 1991, jornadas éstas que organiza todos los años José Rolando Ordóñez Cifuentes.

${ }^{2}$ Para la diferencia entre efectividad y eficacia de las normas ver Correas, Óscar, Introducción a la Sociología Jurídica, Fontamara, México, 1994.

${ }^{3}$ Una explicación más detallada en Correas, Óscar, Crítica de la ideología jurídica, UNAM, México, 1993, y Correas, Óscar, Introducción a la Sociología Jurídica, ob. cit.

${ }^{4}$ Recuérdese que Engels trató esta cuestión en El origen de la familia, el Estado y la propiedad privada, obra de la que existen incontables ediciones.

${ }^{5}$ Sobre el carácter centralizado o descentralizado de la organización social, véase Kelsen, Hans, Teoría General del Estado, Ediciones Coyoacán-UNAM, México, 2004, capítulo primero, y específicamente la página 32.

${ }^{6}$ Sobre las máscaras jurídicas,véase, Kelsen, Hans, «Dios y estado», en El otro Kelsen, Correas, Óscar, México, Ediciones Coyoacán-UNAM, 2004, pp. 243 y ss.

${ }^{7}$ Estos funcionarios constituyen el «cuadro administrativo» del que habla Weber, Max, Economía y Sociedad, FCE, México, 1983, p. 43: «Una asociación de dominación debe llamarse asociación "política" cuando y en la medida en que su existencia y la validez de sus ordenaciones, dentro de un "ámbito geográfico" determinado, estén garantizados de un modo continuo por la amenaza y aplicación de la fuerza física por parte de su cuadro administrativo ... cuando y en la medida en que su cuadro administrativo mantenga con éxito la pretensión al «monopolio legítimo» de la coacción física para el mantenimiento del orden vigente».

${ }^{8}$ Véase Engels, Federico, El origen de la familia, la propiedad privada y el estado, Editorial Progreso Moscú, sin fecha, p. 173: «El segundo rasgo característico es la institución de una "fuerza pública" que ya no es el pueblo armado. Esta fuerza pública se hace necesaria porque desde la división de la sociedad en clases es ya imposible un organización armada espontánea en la población ... Esta fuerza pública existe en todo Estado; y no está formada sólo por hombres armados, sino también por aditamentos materiales, las cárceles y las instituciones coercitivas de todo género, que la sociedad gentilicia no conocía ....se fortalece a medida que los antagonismos de clase se exacerban...».

${ }^{9}$ Vale la pena notar que Kelsen dijo innumerables veces que una norma es siempre el «sentido de un acto de voluntad» usando «sentido» como Weber, que sin duda es más cercano a los científicos sociales.

${ }^{10}$ Permítaseme remitirme en este punto a Correas, Óscar, Pluralismo Jurídico, alternatividad, y derecho indígena, Ediciones Coyoacán, México, 2004.

${ }^{11}$ Permítaseme aquí remitirme a Correas, Óscar, Derecho Indígena Mexicano I, Ediciones Coyoacán-UNAMCEIICH, México, 2007. 
12 Ya quedó dicho que estos funcionarios no están separados de la producción, y, por tanto, el sistema normativo es descentralizado.

Fecha de recepción: 10 de diciembre de 2009.

Fecha de aceptación: 13 de junio de 2010. 